\title{
Utilizing AHP: Resource Allocation Problem in Cloud
}

\author{
Avtar Singh \\ National Institute of Technology \\ Hamirpur, HP, India
}

\author{
Kamlesh Dutta \\ National Institute of Technology \\ Hamirpur, HP, India
}

\begin{abstract}
Cloud Computing is changing the scheme by providing different services to business and government sectors as well as to sole users irrespective of their location. Cloud Computing provides scalable and on demand services to users, but this technology has many challenges. In several applications the last decision is based on the estimate of a number of alternatives in terms of a number of criteria. This problem may become difficult one when criteria are expressed in different tasks or jobs, relevant data are difficult to be quantified. The Analytic Hierarchy Process (AHP) is an effective method dealing with this kind of decision problems. This paper deals with priorities, ranking with consistency method and their results are given through a numerical example. The results show that distributive mode has fast convergence and smaller computational complexity than ideal mode for close system when the AHP method is used in cloud computing applications.
\end{abstract}

\section{Keywords}

Analytic Hierarchy Process, pairwise comparison matrix, Priority vector, Consistency index

\section{INTRODUCTION}

Cloud Computing is becoming an increasingly popular computing model in which computing resources are made available on-demand to the user as needed (Hayes [1]; Mell and Grance [2]). Buyya et al. [3] studied the cloud computing and provide the architecture for creating Clouds with marketoriented resource allocation by leveraging technologies such as Virtual Machines (VMs). Cloud Computing provides many opportunities for enterprises by offering a range of computing services (Armbrust et al.[4], Chieu et al. [5]). The benefits of cloud computing include services on low costs and capital expenditures, increased operational efficiencies, scalability, flexibility and so on. Buyya et al. [6] studied the cloud computing user applications over the internet assigned with available resource allocation. Cloud Computing provides different types of services, which are categories in three main such as I) SaaS (Software as a Service) II) PaaS (Platform as a Service) III) IaaS (Infrastructure as a Service) and provides many chances for enterprises by offering a range of computing services. These chances, still, don't come without challenges. Dynamic resource allocation is also a challenge in Cloud Computing. Martens et al. [7] suggested a complex mathematical decision model associate the selection of cloud computing services in a multi-source scenario. When many users make requests for cloud resources at the same time, then how these requested and other resources will be allocated to users to get resources. This is a challenging task in Cloud Computing. Consider the following (hypothetical) example: a company needs to define business, the technical specification for its cloud applications with various criteria that are important to them. The first step is to structure the problem into a hierarchy depicts in Fig. 1 Level 1 is the overall goal of Business Technical Facilitate (BTF). In level 2 there are four criteria that contribute to the goal, and in level 3 sub criteria are for user's requirement for the applications that are to be evaluated by considering the local priorities on the second level. The criteria important for the Cloud, applications are summaries as: Integration Facilitate (IF): It can be sub criteria to Number of outside systems, Number of hardware devices, accurately integration point, etc. Migration Facilitate (MF): It can be sub criteria for Functional complexity, application size, database size, nonproprietary code etc. Technology Stack (TS): It can be sub criteria to the OS, Database and Runtime. Application Design (AD): It can be sub criteria to Virtualization and loose coupling. AHP estimate a set of applications for cloud fitness.

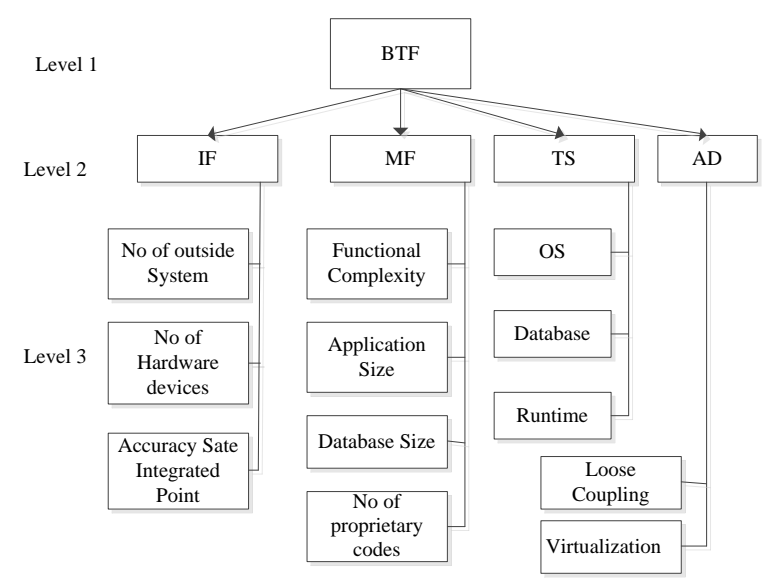

Fig. 1. Decomposition of problem into a hierarchy

The approach is a multi dimensional relating judgment; enterprise applications are estimated in dimensions. These dimensions have a vital effect on a stay/no-stay decision regarding the cloud change of applications. Estimate of an application in each of these dimensions is a multi criteria decision analysis (MCDA); AHP is one of the methods used in MCDA. AHP includes the development of different substitutions based on various criteria, some which may conflict with other options, some which have a contrasting environment can be qualitative or quantitative on complete stability. The methods used in the AHP measure relative priority for a given set of measures on a scale ratio. AHP offers advantages over many other MCDA methods: AHP provides an inclusive building to combine equally quantitative and qualitative measures in the decision-making process. AHP brings an ability to judge the consistency in analysis process as depict in Table 1 that can help reduce inconsistencies and increase objectivity. Analytical Hierarchy Process has been used for resource allocation in Cloud Computing Ergu et al. [8]. Eigenvector method is used for synthesis of AHP method (Saaty, [9-11]) in Cloud Computing. The benefit of this method is that it deduce the weight of the user's tasks accurately. This method assigns a particular priority to each user task, which is further used in assigning Cloud resources to user's tasks. Brijesh Deb [12] discussed about using the Analytic Hierarchy Process to evaluate apps for the cloud to assess enterprise applications for cloud migration. An AHP based model is proposed to task-oriented resource allocation in a cloud computing environment [13]. The tasks are weighted with AHP. The task attributes such as completion 
time, costs, and reliability are compared according to the network bandwidth. Thereafter resource assigned accordingly. The reciprocal evaluation matrix and the induced bias matrix are used to recognize inconsistent components and to make better consistency ratio. In [14], SaaS products are made available in a cloud computing environment that uses AHP to prioritize product characteristic decided by an expert scoring system. The problem review consists of a number, say K, of alternatives and a number, say $\mathrm{N}$, of decision criteria. Each application task can be calculated in terms of the decision criteria and relative weight of each criterion can be valued. Let aij $(\mathrm{i}=1,2,3, \ldots, \mathrm{K}$, and $\mathrm{N}=1,2,3, \ldots, \mathrm{N})$ denote the performance value of the ith alternative (i.e., Ai) in terms of the jth criterion (i.e., $\mathrm{Cj}$ ). Also denote as $\mathrm{Wj}$ the weight of the criterion $\mathrm{Cj}$. Then, the problem can be represented by the following matrix:

\begin{tabular}{|c|c|c|l|l|c|}
\hline \multirow{2}{*}{$\begin{array}{l}\text { Priority } \\
\text { vector }\end{array}$} & \multicolumn{5}{|c|}{ Evaluation Criteria } \\
\cline { 2 - 6 } & $\mathrm{C}_{1}$ & $\mathrm{C}_{2}$ & $\mathrm{C}_{3}$ & $\ldots \ldots \ldots$ & $\mathrm{C}_{\mathrm{N}}$ \\
& $\mathrm{W}_{1}$ & $\mathrm{~W}_{2}$ & $\mathrm{~W}_{3}$ & $\ldots \ldots \ldots$ & $\mathrm{W}_{\mathrm{N}}$ \\
\hline $\mathrm{A}_{1}$ & $\mathrm{a}_{11}$ & $\mathrm{a}_{12}$ & $\mathrm{a}_{13}$ & $\ldots \ldots \ldots$ & $\mathrm{a}_{1 \mathrm{~N}}$ \\
\hline $\mathrm{A}_{2}$ & $\mathrm{a}_{21}$ & $\mathrm{a}_{22}$ & $\mathrm{a}_{23}$ & $\ldots \ldots \ldots$ & $\mathrm{a}_{2 \mathrm{~N}}$ \\
\hline $\mathrm{A}_{3}$ & $\mathrm{a}_{31}$ & $\mathrm{a}_{32}$ & $\mathrm{a}_{33}$ & $\ldots \ldots \ldots$ & $\mathrm{a}_{3 \mathrm{~N}}$ \\
\hline$!$ & $!$ & $!$ & $!$ & $!$ & $!$ \\
\hline $\mathrm{A}_{\mathrm{K}}$ & $\mathrm{a}_{\mathrm{K} 1}$ & $\mathrm{~A}_{\mathrm{K} 2}$ & $\mathrm{a}_{\mathrm{K} 3}$ & $\ldots \ldots \ldots$ & $\mathrm{a}_{\mathrm{KN}}$ \\
\hline
\end{tabular}

Given the above matrix, the problem study is how to decide which application task is the best. A slightly different problem is to find the relative importance of the $\mathrm{K}$ alternatives when they are inspected in terms of the $\mathrm{N}$ criteria combined.

\section{AHP Methodology}

AHP is a mathematical technique used for multi-criteria decision-making. This is better than other multi-criteria techniques. It designed to incorporate tangible as well as nontangible factors, especially where the subjective judgments of different individuals constitute an important part of decision making (Saaty TL [9], Saaty TL [10] and Saaty TL [11]. The following Table 1 shows the values and their explanation used for the comparison of relevant values of the elements of a typical AHP model. Relative priorities are assigned for different criteria using the 1-9 scale of AHP. Priorities are first decided for criteria and then for individual sub-criteria under each criteria. The sum of priorities of individual criteria in a certain level is normalized to one. Sub-criteria are locally priorities.

Table 1 Fundamental scales 1 to 9

\begin{tabular}{|c|c|c|}
\hline Intensity & Definition & Explanation \\
\hline 1 & Equal importance & $\begin{array}{c}\text { Two elements contribute } \\
\text { equally to objective }\end{array}$ \\
\hline 3 & $\begin{array}{c}\text { Moderate } \\
\text { importance }\end{array}$ & $\begin{array}{c}\text { Slightly importance to } \\
\text { one element over } \\
\text { another }\end{array}$ \\
\hline 5 & Strong importance & $\begin{array}{c}\text { Strongly importance to } \\
\text { one element over } \\
\text { another }\end{array}$ \\
\hline
\end{tabular}

\begin{tabular}{|c|c|c|}
\hline 7 & $\begin{array}{c}\text { Very strong or } \\
\text { demonstrated } \\
\text { importance }\end{array}$ & $\begin{array}{c}\text { Very strongly } \\
\text { importance to one } \\
\text { element over another }\end{array}$ \\
\hline 9 & $\begin{array}{c}\text { Extreme } \\
\text { importance }\end{array}$ & $\begin{array}{c}\text { Extremely importance to } \\
\text { one element over } \\
\text { another }\end{array}$ \\
\hline $2,4,6,8$ & $\begin{array}{c}\text { Intermediate } \\
\text { importance }\end{array}$ & $\begin{array}{c}\text { Weak, Moderate plus, } \\
\text { Strong plus, Very } \\
\text { Strong }\end{array}$ \\
\hline
\end{tabular}

Singh et al. proposed technique on weight priorities and ranking mechanism of task based consistency and multi criteria evaluation hierarchy [15]. Li et al. discussed drawbacks of AHP in its invariable weight system and improved ranking approach [16]. The cons of the AHP technique are the limitation scale that uses 9-point. Sometimes, the decision maker might find difficult to differentiate among them and express for example, whether one alternative is 7 or 8 times more important than another. Carlucci et al. [17] Proposed scenario where you need to prioritize two requirements having different weight at different time and the limitations of AHP in a practical environment.

\subsection{Consistency}

Saaty has proposed a consistency index (CI) which is related to the eigenvalue method.

$\mathrm{CI}_{\mathrm{n}}=\frac{\lambda_{\max }-\mathrm{n}}{\mathrm{n}-1}$

where $n=$ dimension of the matrix, $\lambda_{\max }=$ maximum eigenvalue

The consistency ratio, the ratio of $\mathrm{CI}$ and RI, is given by:

$\mathrm{CR}=\mathrm{CI} / \mathrm{RI}$

where RI is the random index (the average CI of 500 randomly filled matrices)

If $\mathrm{CR}$ is less than $10 \%$, then the matrix can be considered as having an acceptable consistency. (Saaty TL [9] and Rao R.V. [18]) calculated the random indices shown in Table 2:

Table 2 Random indices (RI)

\begin{tabular}{|c|c|c|c|c|c|c|c|c|}
\hline $\mathbf{n}$ & 3 & 4 & 5 & 6 & 7 & 8 & 9 & 10 \\
\hline $\mathbf{R I}$ & 0.58 & 0.89 & 1.12 & 1.24 & 1.32 & 1.41 & 1.45 & 1.49 \\
\hline
\end{tabular}

It gives the average inconsistency. Mathematically, inconsistency is not, but a recycling of the largest eigenvalue. Since $\lambda_{\max } \geq n$ and $\mathrm{CI}_{n}$ is always non-negative. The inconsistency index in its own has no meaning, unless we compare it with some benchmark to determine the magnitude of the deviation from consistency. Yet, the revision process stops at the requirement that consistency ratio $\mathrm{CR} \leq 0.1$, which may not obtain a superior CR. After the options are compared with each other in relations of each one of the decision criteria and the individual priority vectors are derived, the synthesis step is taken. The priority vectors become the columns of the decision matrix (not to be confused with the judgment matrices with the pairwise comparisons). The weights of importance of the criteria are also determined by using pairwise comparisons. Therefore, if a problem has $\mathrm{M}$ alternatives and $\mathrm{N}$ criteria, then the decision maker is required to construct $\mathrm{N}$ judgment matrices (one for each criterion) of order MxM and one judgment matrix of 
order $\mathrm{NxN}$ (for the $\mathrm{N}$ criteria). Finally, Triantaphyllou et al. [19] given a decision matrix the final priorities, denoted by $\mathrm{A}_{\mathrm{AHP}}^{\mathrm{i}}$, of the alternatives in terms of all the criteria combined are determined according to the following formula (3). The AHP method has pros to support group decision making through accord by calculating the geometric mean of the individual pairwise comparisons.

$$
A_{A H P}^{i}=\sum_{j=1}^{N} a_{i, j} w_{j}, \quad{ }_{\text {for }} i=1,2,3, \ldots \ldots \ldots . M
$$

\subsection{Alternative way to Determine Priority Vector}

There are numerous methodology presented in the literature for deriving priority weights in the AHP. Gao et al. [20] practically, the most common approach is the originally proposes eigenvector method have been proposed to associate a priority vector with a given positive reciprocal matrix A.

\subsubsection{Sum Method (SM)}

Let $\mathrm{A}=\left(\mathrm{a}_{\mathrm{ij}}\right)$ a is $n \times n$ judgement matrix. Firstly we normalize the column vectors in the judging matrix and then add the normalized matrix in rows. The result should be normalized again to get the eigenvector:

$$
w_{i}=\frac{1}{n} \sum_{j=1}^{N} \frac{a_{i j}}{\sum_{k=1}^{n} a_{k j}}, i=1,2 \ldots \ldots \ldots n
$$

\subsubsection{Geometric Mean Method (GM)}

The geometric mean method is defined by

$$
w_{i}=\frac{\left(\prod_{j=1}^{n} a_{i j}\right)^{\frac{1}{n}}}{\sum_{k=1}^{n}\left(\prod_{j=1}^{n} a_{k j}\right)^{\frac{1}{n}}}(i=1,2, \ldots \ldots . n)
$$

The geometric mean solution can be derived as the solution of the follow optimization problem:

$$
\min \sum_{i=1}^{n} \sum_{j=1}^{n}\left[\ln a_{i j}-\ln \left(\frac{w_{i}}{w_{j}}\right)\right]^{2}
$$

s.t. $\sum_{i=1}^{n} w_{i}=1, w_{i}>0, i=1,2 \ldots \ldots \ldots n$

\subsubsection{Eigen Vector Method (EM)}

The eigenvector is defined by

$$
\mathrm{AW}=\lambda_{\max } \mathrm{W}
$$

where $\lambda_{\max }$ is the largest eigenvalue of A. It must be noted that this eigenvector solution is normalized additively, i. e.

$$
\sum_{i=1}^{n} w_{i}=1
$$

\subsubsection{New Least Squares Method}

The method of logarithmic least squares (NLSM) determines a priority vector by minimizing the Frobenius norm of $\left[\log \left(\frac{a_{i j} x_{j}}{x_{i}}\right)\right]$ $\min _{x>0} \sum_{i, j=1}^{n}\left[\log a_{i j}-\log \left(\frac{x_{i}}{x_{j}}\right)\right]^{2}$

The four methods SM, EM, GM and NLSM produce the same priority vector when $A$ is consistent, but overall the two methods give different priority vectors and rankings. All the diagonal relevant value elements of the matrix are 1 means compared to themselves. Comparisons are done for both the values of upper and lower triangular triangular matrix. Here is an example:

$$
\left[\begin{array}{ccc}
1 & 2 & 5 \\
1 / 2 & 1 & 7 \\
1 / 5 & 1 / 7 & 1
\end{array}\right]
$$

\begin{tabular}{|l|l|l|l|}
\hline SM & GM & EM & NLSM \\
\hline 0.5364 & 0.5415 & 0.5415 & 0.5159 \\
\hline 0.3836 & 0.3816 & 0.3816 & 0.3690 \\
\hline 0.0800 & 0.0768 & 0.0768 & 0.0770 \\
\hline
\end{tabular}

$\left[\begin{array}{ccccc}1 & 1 / 7 & 1 / 2 & 1 / 8 & 2 \\ 7 & 1 & 3 & 1 & 8 \\ 2 & 1 / 3 & 1 & 1 / 4 & 5 \\ 8 & 1 & 4 & 1 & 5 \\ 1 / 2 & 1 / 8 & 1 / 5 & 1 / 5 & 1\end{array}\right]$

\begin{tabular}{|l|l|l|l|}
\hline SM & GM & EM & NLSM \\
\hline 0.0620 & 0.0616 & 0.0612 & 0.0599 \\
\hline 0.3754 & 0.3839 & 0.3743 & 0.3623 \\
\hline 0.1327 & 0.1328 & 0.1342 & 0.1325 \\
\hline 0.3806 & 0.3801 & 0.3869 & 0.3673 \\
\hline 0.0447 & 0.0416 & 0.0434 & 0.0431 \\
\hline
\end{tabular}

However, the example shows that for $\mathrm{n}>3$, the priority vector and criteria rankings produced by SM, EM, GM and NLSM need not be the same. In the previous work selection of application was based on priorities of features and ranking in decreasing order but above four methods for calculating the priorities that can effect ranking as demonstrated in two examples. With AHP the decision problem is broken down into a number of sub criteria, within which and between which a significant number of pairwise comparisons need to be completed. This method has a cons in a cloud computing environment as the number of pairwise comparisons to be made, may become very large ( $(n-1) / 2)$, and thus become a long task. In the Eigenvector method when the size of comparison matrix is large, then inconsistency occurs in large amount by Srdjevic [13]. In Cloud Computing there are thousands of users which use cloud resources at one time. Hence the size of comparison matrix using this method will be larger and there will be lots of inconsistencies in priorities of the user's tasks by Singh et al. [15].

\section{A Numerical Example}

An example considering the following hypothetical situation. In the real world, decision-making problems are filled with uncertainty. Selecting BTF for its cloud applications with various criteria that are important to them, there are three alternative configuration applications $\mathrm{A}, \mathrm{B}$ and $\mathrm{C}$. That following the judgment matrix when three alternative configurations are examined in terms of this criterion. The three alternative applications described earlier need to be 
evaluated in terms of the four decision criteria: such as $\mathrm{C} 1$ : IF, $\mathrm{C} 2$ : MF, C3: TS and C4: AD. If more criteria are needed to be considered, this example can be extended accordingly. The following matrices represent corresponding judgment matrices with the pairwise comparisons. The corresponding priority vectors (for the individual criteria) and the consistency coefficients are given as below Table 3 .

Table 3 Pairwise comparison matrices for the criteria C1, $\mathrm{C} 2 \mathrm{C3}$ and $\mathrm{C} 4$

\begin{tabular}{|c|c|c|c|c|c|}
\hline \multicolumn{6}{|c|}{ C1.IF of task with weight } \\
\hline C1 & $\mathbf{A}$ & B & C & $\begin{array}{c}\text { Distributed } \\
\text { Priority }\end{array}$ & $\begin{array}{c}\text { Ideal } \\
\text { Priority }\end{array}$ \\
\hline $\mathbf{A}$ & 1 & 5 & 9 & 0.7352 & 1.000 \\
\hline B & $1 / 5$ & 1 & 4 & 0.1994 & 0.2712 \\
\hline C & $1 / 9$ & $1 / 4$ & 1 & 0.0654 & 0.0889 \\
\hline \multicolumn{6}{|c|}{ C2. MF of task with weight } \\
\hline C2 & A & B & $\mathbf{C}$ & $\begin{array}{c}\text { Distributed } \\
\text { Priority }\end{array}$ & $\begin{array}{c}\text { Ideal } \\
\text { Priority }\end{array}$ \\
\hline $\mathbf{A}$ & 1 & 6 & 4 & 0.6853 & 1.0000 \\
\hline B & $1 / 6$ & 1 & $1 / 3$ & 0.2214 & 0.1363 \\
\hline C & $1 / 4$ & 3 & 1 & 0.1335 & 0.3230 \\
\hline \multicolumn{6}{|c|}{ C3. TS of task with weight } \\
\hline $\mathbf{C 3}$ & $\mathbf{A}$ & B & C & $\begin{array}{c}\text { Distributed } \\
\text { Priority }\end{array}$ & $\begin{array}{c}\text { Ideal } \\
\text { Priority }\end{array}$ \\
\hline A & 1 & 4 & $1 / 5$ & 0.1994 & 0.2712 \\
\hline B & $1 / 4$ & 1 & $1 / 9$ & 0.0654 & 0.0889 \\
\hline C & 5 & 9 & 1 & 0.7352 & 1.0000 \\
\hline \multicolumn{6}{|c|}{ C4. AD of task with weight } \\
\hline C4 & A & B & C & $\begin{array}{l}\text { Distributed } \\
\text { Priority }\end{array}$ & $\begin{array}{c}\text { Ideal } \\
\text { Priority }\end{array}$ \\
\hline $\mathbf{A}$ & 1 & 9 & 6 & 0.5774 & 1.0000 \\
\hline B & $1 / 9$ & 1 & $1 / 3$ & 0.1595 & 0.0913 \\
\hline C & $1 / 6$ & 3 & 1 & 0.2631 & 0.1270 \\
\hline
\end{tabular}

The two ways of synthesizing are shown in Table 5 and Table 6 for both distributive and idealized priority vectors with normalization and after normalization with their task for each criteria of the three applications do not suggest same ranking. The idealized priority vector is achieved by dividing each element of the distributive priority vector of its largest element. The composite priority vector for the customers is achieved by multiplying each priority vector by the priority of the corresponding criterion, adding across all the criteria for each customer and then normalizing. When use the distributive priority vectors, that yields $\mathrm{A}=0.8098, \mathrm{~B}=0.1649$, and $\mathrm{C}=0.2627$. Thus, application $\mathrm{A}$ is preferred to application $\mathrm{B}$ and $\mathrm{C}$ in the ratios: $0.8098 / 0.1649$ and $0.8089 / 0.2627$, respectively. When use the idealized priority vector that yields $\mathrm{A}=0.8063, \mathrm{~B}=0.1948, \mathrm{C}=0.3659$ and $\mathrm{A}$ is again the most preferred. If the priority is known in advance than distributive mode is the only method that will recover these priorities. Finally, the following judgment matrix in the case of comparing the importance of the four decision criteria are calculated depict in Table 4.
Table 4 Distributed priority C1,C2,C3,C4

\begin{tabular}{|c|c|c|c|c|c|}
\hline $\begin{array}{c}\text { The four } \\
\text { criteria }\end{array}$ & C1 & C2 & C3 & C4 & $\begin{array}{c}\text { Distributed } \\
\text { Priority }\end{array}$ \\
\hline C1 & 1 & 5 & 3 & 7 & 0.5438 \\
\hline C2 & $1 / 5$ & 1 & $1 / 3$ & 5 & 0.1413 \\
\hline C3 & $1 / 3$ & 3 & 1 & 6 & 0.2657 \\
\hline C4 & $1 / 7$ & $1 / 5$ & $1 / 6$ & 1 & 0.0492 \\
\hline
\end{tabular}

As it was mentioned earlier, the previous priority vectors are used to form the entries of the decision matrix for this problem. The decision matrix and the resulted final priorities (which are calculated according to the formula (3) are as follows:

Matrix and Solution when the Original AHP is used is depicted in Table 5:

Table 5 Distributed Mode with Normalization

\begin{tabular}{|c|c|c|c|c|c|c|}
\hline $\begin{array}{c}\text { The } \\
\text { four } \\
\text { criteria }\end{array}$ & $\begin{array}{c}\mathbf{C 1} \\
\mathbf{0 . 5 4 3 8}\end{array}$ & $\begin{array}{c}\mathbf{C 2} \\
\mathbf{0 . 1 4 1 3}\end{array}$ & $\begin{array}{c}\mathbf{C 3} \\
\mathbf{0 . 2 6 5 7}\end{array}$ & $\begin{array}{c}\mathbf{C 4} \\
\mathbf{0 . 0 4 9 2}\end{array}$ & $\begin{array}{c}\text { Distributed } \\
\text { Mode }\end{array}$ & Normalization \\
\hline A & 0.7352 & 0.6853 & 0.1994 & 0.5774 & 0.8098 & $\mathbf{0 . 6 5 8 3}$ \\
\hline B & 0.1994 & 0.2214 & 0.0654 & 0.1595 & 0.1649 & $\mathbf{0 . 1 3 4 0}$ \\
\hline C & 0.0654 & 0.1335 & 0.7352 & 0.2631 & 0.2627 & $\mathbf{0 . 2 1 3 5}$ \\
\hline
\end{tabular}

Matrix and Solution when the Ideal Mode AHP is used is depicted in Table 6:

Table 6 Ideal Mode After Normailization

\begin{tabular}{|c|c|c|c|c|c|c|}
\hline $\begin{array}{c}\text { The four } \\
\text { criteria }\end{array}$ & $\begin{array}{c}\mathbf{C 1} \\
\mathbf{0 . 5 4 3 8}\end{array}$ & $\mathbf{\mathbf { C 2 }}$ & $\mathbf{C 3}$ & $\mathbf{C 4}$ & $\begin{array}{c}\text { Ideal } \\
\text { Mode }\end{array}$ & $\begin{array}{c}\text { After } \\
\text { Normalization }\end{array}$ \\
\hline $\mathbf{A}$ & 1.000 & 1.0000 & 0.2712 & 1.000 & 0.8063 & $\mathbf{0 . 5 9 4 5}$ \\
\hline $\mathbf{B}$ & 0.2712 & 0.1363 & 0.0889 & 0.0913 & 0.1948 & $\mathbf{0 . 1 4 3 2}$ \\
\hline $\mathbf{C}$ & 0.0889 & 0.3230 & 1.000 & 0.1270 & 0.3659 & $\mathbf{0 . 2 6 9 0}$ \\
\hline
\end{tabular}

Millet and Saaty gave some way to use the normalization [21]. In a closed source system (that is, no choice will be added or removed), then the distributive mode is suggested. In an open source system (that is options can be added or removed) and chance to choose the options to be dependent on other options (alternative, accept the rank reversal phenomenon), then the distributive mode is specified. In an open source system not want that other options to affect the outcome, then the ideal mode is suggested. Cost of open source system is better than close source system. There are some issues in open source system regarding design and documentation discussed by Ishizaka et al. [22]. Based on these clarifications, the choice has been modified to support the two modes. Therefore, the application A compiled by application $\mathrm{C}$ which complied by application B. Observe that although both the original AHP and the ideal mode AHP give the same ranking for the three options, they allocated different final priorities for these options. The section describes some cases in which the original AHP (and in a similar manner the ideal mode AHP) can show ranking irregularities for some decision making problems. 


\section{CONCLUSION}

The AHP provides a convenient approach for solving complex problems with cloud computing. It is also concluded from the above results that in cloud computing problems one should be cautious in selecting the priorities and ranking. Finally, motivation was to introduce and analyzed a class of inconsistency measures for positive reciprocal matrices and relating the choice of proper methods for the extraction of weights. Comparison of two modes shows that distributive mode has fast convergence and smaller computational complexity than ideal mode for close system with AHP method. The fact depicts that, closer final priority values, more cautious in decision making for selecting applications. The future work includes an automation tool that support AHP method for cloud application which can meets all the business and strategies of the company.

\section{REFERENCES}

[1] Hayes Brain. (2008) Cloud computing. Commun ACM, 51(7):9-11.

[2] Mell P., Grance T. (2011) The NIST definition of cloud computing. Special Publication, 2011, pp. 800-145.

[3] Buyya R, Yeo C.S., Srikumar V, James B, Ivona B. (2009) Cloud computing and emerging IT platforms: vision, hype, and reality for delivering computing as the 5th utility. Future Gener Comput Syst, 2009, 25(6):599616.

[4] Armbrust M., Fox A., Griffith R., Joseph A., Katz R., Konwinski A. ... Zaharia M. (2009) Above the clouds: A Berkeley view of cloud computing. Technical Report, University of California at Berkeley.

[5] Chieu T. C., Mohindra A., Alexei A., Karve A.A., Segal A.A.(2009) Dynamic scaling of web applications in a virtualized cloud computing environment. In Proceedings of the IEEE International Conference on e-Business Engineering, pp.281-286.

[6] Buyya R., Broberg J., Goscinski A. (2011) Cloud computing: Principle and paradigm. John Wiley\& Sons.

[7] Martens, B., and Teuteberg, F. (2012) Decision-making in cloud computing environments: a cost and risk based approach. Information Systems Frontiers, 14, 4:871-893.

[8] Ergu D, Kou G, Peng Y, Shi Y, Shi Y. (2011) The analytic hierarchy process: task scheduling and resource allocation in cloud computing environment, J. Supercomput. Springer ScienceBusiness Media, pp. 835848.

[9] Saaty TL. (2009) A scaling method for priorities in hierarchical structures. J of Mathematical Psychology, 1977, pp. 234-281.
[10] Saaty TL. (1990) How to make a decision: the analytic hierarchy process. Eur J Oper Res, 48(1): 9-26.

[11] Saaty TL. (2003) Decision-making with the AHP: Why is the principal eigenvector necessary. Eur J Oper Res, 145:85-89.

[12] Brijesh Deb. (2010) Assess enterprise applications for cloud migration Using the Analytic Hierarchy Process to evaluate apps for the cloud, white paper IBM Corporation, pp.1-11.

[13] Srdjevic B. (2005) Combining different prioritization methods in the analytic hierarchy process synthesis. Computers \& Operations Research, pp. 1897-1919.

[14] Godse, M. and Mulik, S. (2009) An approach for selecting Software-as a- Service (SaaS) product. In Proceedings of the IEEE International Conference on Cloud Computing, pp. 155-158.

[15] Singh A, Dutta K., Singh A. (2014) Resource allocation in cloud computing environment using AHP technique. International journal of cloud Applications and Computing, 4(1): 33-44.

[16] Li C, Li H, Sun Y, Jia Y. (2008) An Improved Ranking Approach to AHP Alternatives Based on Variable Weights, Intelligent Control and Automation, pp. 82558260 .

[17] Carlucci D, Schiuma G. (2007) Knowledge assets value creation map assessing knowledge assets value drivers using AHP. Expert Systems with Applications, 32: 814821.

[18] Rao R.V. (2013) Decision Making in the Manufacturing Environment Using Graph Theory and Fuzzy Multiple Attribute Decision Making Methods, Springer Series in Advanced Manufacturing, Verlag London: 2013.

[19] Triantaphyllou E, Mann S.H. (1995) Using the analytic hierarchy process for decision making in engineering applications: some challenges. Inter'l Journal of Industrial Engineering: Applications and Practice, 2(1): $35-44$

[20] Gao S, Zhang Z, Cao C. New Methods of Estimating Weights in AHP, Proceedings of the International Symposium on Information Processing, 2009, pp.201204.

[21] Millet, I., Saaty, T. On the relativity of relative measuresaccommodating both rank preservation and rank reversals in the AHP. European Journal of Operational Research, 2000, 121(1): 205-212.

[22] Ishizaka, A., Labib, A. (2009) Analytic Hierarchy Process and Expert Choice: Benefits and limitations. Operational Research Society. 2009; 22, 4:201-220. 